\title{
ESTRATÉGIAS DE POLIDEZ NO GÊNERO RESENHA ACADÊMICA
}

\section{POLITENESS STRATEGIES IN ACADEMIC REVIEWS}

\section{RESUMO}

Gabriel Santana

Kazue Saito M. de Barros UFPE / Nelfe / CNPq

Desde a publicação seminal de Brown e Levinson (1987), diversas pesquisas vêm sendo feitas sobre polidez e construção da face na conversação. Mais recentemente, tem ganhado força um interesse de estudo voltado para as estratégias polidez no âmbito da modalidade escrita de língua - interesse no qual este trabalho se insere. Pretende-se contribuir com a análise de um gênero do domínio acadêmico-científico: a resenha, ainda pouco estudada sob a perspectiva da polidez. Buscamos identificar, primeiramente, algumas das estratégias mais recorrentes em cinco resenhas, publicadas em diferentes periódicos Qualis A. Além disso, tentamos identificar correlações entre aspectos composicionais do gênero e pontos de ocorrência das estratégias de polidez. Para o estudo dos fenômenos da polidez, tomamos o modelo teórico baseado no trabalho de KerbratOrecchioni (2006), que, tentando aperfeiçoar a construção teórica clássica de Brown e Levinson (1987), argumenta que há tanto uma polider positiva, que opera no sentido da valorização das faces, quanto uma polidez negativa, que opera no sentido de minimizar os efeitos das ameaças às faces, dividindo-se em procedimentos substitutivos e acompanbantes. Assumindo ainda os enunciados não como previamente polidos ou impolidos, mas como sendo percebidos pelos participantes como polidos ou não, compreendemos ser fundamental interpretar as bases das percepções dessas estratégias, que se traduzem por expectativas de comportamento, conceito que tomamos de empréstimo de Spencer-Oatey (2005) para estudarmos também como os autores das resenhas categorizam seus possíveis interlocutores: autor resenhado, especialistas na área, leitores comuns, etc. Mesmo entendendo que os gêneros assumem formas relativamente estáveis (MARCUSCHI, 2008), tomamos metodologicamente o modelo de resenha acadêmica descrito por Mota-Roth e Hendges (2010): Apresentação; Descrição; Avaliação; Recomendação (ou não). Os resultados obtidos aparentam indicar que existem, de fato, correlações entre pontos de ocorrência das estratégias, suas respectivas funções sociointeracionais e a estrutura composicional da resenha.

PALAVRAS-CHAVE: Polidez; Face; Resenha acadêmica.

\section{ABSTRACT}

Since the seminal publication of Brown \& Levinson (1987), there have been many studies on politeness and face construction in conversations. More recently, an interest in studying politeness strategies in written texts has been growing - interest in which this work fits. We intend to contribute with the analysis of an academic-scientific genre: the review, as yet little studied from a politeness perspective. Firstly, we attempted to identify the politeness strategies that are the most common in five reviews, published in different Qualis A journals. After that, we tried to identify relations between formal aspects of the texts and the occurrence points of the politeness strategies. We took as a theoretical model the studies of Kerbrat-Orecchioni (2006), that tried to make an improvement on the model of Brown \& Levinson (1987), affirming that there is a positive politeness, in which some face flattering strategies occur, and a negative politeness, in which some 'face threatening acts' are minimized. Also, assuming that texts are not a priori polite or impolite, but perceived by participants as polite or not, we understand that it is fundamental to interpret the perception basis of these strategies, that can be called behavioral expectations, a concept that we took 
from Spencer-Oatey (2005) to study how authors of reviews categorize their interlocutors: book author, specialists, common readers, etc. Even understanding that genres assume some relatively stable forms (MARCUSCHI, 2008), we took for methodological purposes the review model described by Mota-Roth \& Hendges (2010): Presentation; Description; Evaluation; Recommendation (or not). Some preliminary analysis seems to show that there are, indeed, relations between occurrence points of the strategies, their interactional functions and formal aspects of the genre.

KEYWORDS: Politeness; Face; Academic reviews.

\section{INTRODUÇÃO}

Esta produção tem sua origem num projeto de pesquisa que está sendo desenvolvido junto ao Núcleo de Estudos Linguísticos da Fala e da Escrita - Nelfe, com o apoio do CNPq e sob supervisão da Profa. Dra. Kazue S. M. de Barros, que se intitula "(Im)polidez e Atenuação em Contextos Institucionais". Inserida no projeto maior, a pesquisa "Estratégias de (im)polidez em resenhas de artigos científicos" (Pibic UFPE/CNPq) em que se ancora este trabalho, além de possuir a pretensão de divulgar alguns dos principais resultados da investigação sobre (im)polidez em resenhas científicas, visa a contribuir para a pesquisa principal, com a análise de um gênero escrito do domínio acadêmico-científico, a resenha, ainda pouco estudado na perspectiva da polidez.

Antes de tudo, tentamos localizar e identificar algumas das estratégias de polidez mais recorrentes em 5 (cinco) resenhas, publicadas em diferentes periódicos Qualis A da área de Letras/Linguística - textos esses que compõem o corpus da pesquisa. Buscamos identificar também algumas possíveis correlações entre os pontos de ocorrência das estratégias de polidez, suas respectivas funções sociointeracionais, seus propósitos numa possível relação interpessoal entre autor-leitores e os aspectos composicionais do gênero resenha acadêmica.

A fundamentação teórica adota, antes de tudo, uma perspectiva mais interacionista com base em estudos como o de Spencer-Oatey (2005), que defende que os enunciados não são inerentemente polidos ou impolidos, mas são, na verdade, percebidos pelos participantes como polidos ou não. Assim, torna-se de fundamental importância buscar interpretar as bases das percepções dessas estratégias, que se traduzem por expectativas de comportamento - conceito importante para o estudo da polidez na modalidade escrita -, de forma dinâmica e não diretamente vinculada ao código linguístico. Também importante para a compreensão dos fenômenos da polidez em textos escritos é o conceito de partilhamento de conbecimento, que pode ser compreendido como o julgamento que é feito pelos interlocutores sobre os conhecimentos que estão sendo partilhados ou não em determinada situação social (BARROS, 2009).

Apesar de compreendermos o fenômeno da polidez de forma interacionista, o modelo teórico de polidez linguística assumido neste trabalho toma como base os estudos feitos por Kerbrat-Orecchioni (2006), que, buscando aperfeiçoar o aparato teórico clássico de Brown e Levinson (1987), argumenta que, na negociação das faces, lança-se mão: (i) tanto de uma polidez positiva, que opera no sentido da valorização das faces e da maximização da harmonia na interação, trabalhando com a apreciação de possíveis $\mathrm{FFAs}^{1}$; (ii) quanto de uma polidez negativa, que opera no sentido da mitigação das ameaças às faces e da preservação da harmonia, atenuando os possíveis efeitos de um FTA ${ }^{1}$. A fundamentação teórica se justifica pois toma-se como prática metodológica nos estudos do Nelfe, submeter os mesmos dados a múltiplas análises, sob diferentes pontos de vista, para garantir resultados mais confiáveis e consistentes.

\footnotetext{
${ }^{1}$ Estes conceitos serão discutidos mais profundamente no subitem “2.1. Noções de 'face', 'FTA' e 'FFA”'.
} 
Previamente, pode-se levantar a hipótese de que, de fato, existem algumas correlações entre os aspectos composicionais do gênero resenha e os pontos de ocorrência das estratégias de polidez postas em análise. Esta hipótese poderá ser percebida de forma mais evidente quando observarmos, a título de exemplo, algumas estratégias que se direcionam reincidentemente ao autor resenhado e à sua obra, nos parágrafos iniciais e nos parágrafos finais.

\section{Conceitos fundamentais para a polidez na escrita}

É inegável que, atualmente, a maior parte dos estudos sobre as estratégias de polidez possuem um enfoque na modalidade oral de uso da língua, na fala. Para podermos estudar tais fenômenos com um escopo na modalidade escrita, é necessário fazermos algumas observações mais específicas e trabalharmos de forma mais concentrada em cima de conceitos que tenham uma maior relevância para as manifestações da polidez nos textos escritos. Dois conceitos bastante relevantes para fazermos este enfoque são os de expectativas de comportamento, para o qual nos apoiaremos em Spencer-Oatey (2005), e partilhamento de conbecimento, no qual assumiremos como base teórica os estudos de Marcuschi (2003) e Barros (2009).

\subsection{Expectativas de comportamento}

Tomamos os fenômenos da polidez, antes de tudo, de forma mais abrangente, compreendendo seus efeitos dentro de um fenômeno mais preocupado com a construção da relação interpessoal dentro de maneira sociointerativamente situada nos textos em análise. Apesar de assumirmos um aparato teórico mais tradicional, tal como em Kerbrat-Orecchioni (2006), tomaremos de empréstimo a conceituação que Spencer-Oatey (2005) faz ao afirmar que os enunciados não são polidos (ou não) de maneira prévia ou imanente, mas são, na verdade, percebidos pelos interlocutores presentes na interação como (im)polidos. É por esse motivo que se faz necessário buscar interpretar quais seriam as bases das percepções dessas estratégias, que se traduzem pelo conceito de expectativas de comportamento, apresentando-se de forma dinâmica na interação, e não diretamente vinculada a determinado código linguístico.

As expectativas de comportamento estão ligadas aos princípios da equidade e do envolvimento. O princípio da equidade se constitui da crença fundamental dos interlocutores de que eles devem ter a consideração pessoal dos outros e devem ser tratados de forma justa (SPENCER-OATEY, 2005); já os mecanismos de envolvimento - ou de sua ausência - se efetuam por meio de elementos como prolixidade, discurso indireto e omissão de informações elementos que, inicialmente, eram compreendidos como sendo da fala, mas que, segundo Tannen (1984), tem a ver de fato com a relação interpessoal -, além do endereçamento direto e do leitor presumido.

Essas noções relacionadas à expectativa de comportamento são essenciais para esta pesquisa, pois trabalharemos com a interpretação dessas expectativas por parte do autor da resenha; ou seja, buscaremos compreender: (i) as prováveis expectativas do autor da resenha no que diz respeito às reações do autor da obra resenhada, do tradutor (quando houver) e de especialistas da área; (ii) as prováveis expectativas do autor no que se refere às reações do leitor comum; (iii) e também, com menor ênfase, as antecipações feitas pelo autor da resenha acerca das expectativas que o autor (e o tradutor) resenhado(s) e os leitores comuns possuem, i.e., uma antecipação do que todos esses interlocutores esperam ler.

\subsection{Partilhamento de conhecimento}

Através dessa compreensão dos julgamentos subjetivos sobre a adequação social dos comportamentos linguísticos, também se faz possível entendermos o julgamento que é feito 
pelos interlocutores sobre os conhecimentos que estão sendo partilhados ou não em determinada situação social (de leitura, no caso), isto é, o partilhamento de conhecimento (BARROS, 2009). Especificando melhor esse conceito, Marcuschi (2003, p.16) argumenta que "os esquemas comunicativos e a consecução de objetivos exigem partilhamentos e aptidões cognitivas que superam em muito o simples domínio da língua em si", e o autor cita como alguns deles "O envolvimento cultural e o domínio de situações sociais".

No tipo de pesquisa na qual se insere este trabalho, é possível percebermos essa noção: no partilhamento ou não do código linguístico (em textos acadêmicos, isto se encontra na excessiva explicação de determinadas expressões teóricas ou jargões de alguma área de pesquisa, por exemplo); no partilhamento ou não de uma notícia ou de um fato; no partilhamento ou não da leitura de um texto científico ou literário; no partilhamento ou não de uma filiação ideológica; no partilhamento ou não de determinada função social ou determinada profissão etc.

\section{Estratégias linguísticas de polidez}

Um dos avanços mais marcantes nos estudos sobre linguagem e interação verbal foi a percepção do funcionamento da polidez dentro das situações de conversação, noção que expandiremos aqui para a modalidade escrita de língua. Atualmente, há a compreensão dentro dos estudos da análise da conversação de que é impossível detalhar de forma integral o que ocorre nas trocas comunicativas sem levar em conta alguns princípios relacionados à polidez (KERBRAT-ORECCHIONI, 2006).

É por tal relevância deste conceito para os estudos sobre as trocas comunicativas que buscaremos tratar aqui de forma suficientemente detalhada as suas manifestações linguísticas, esmiuçando alguns dos procedimentos empreendidos pelos interlocutores para a sua realização. Antes de qualquer especificação, devemos, no entanto, detalhar alguns conceitos teóricos que embasam a noção de polidez linguística, sendo eles as noções de face, Face Threatening Acts e Face Flattering Acts.

\subsection{Noções de "face", "FTA" e "FFA"}

Um conceito primordial para compreendermos toda a teorização acerca das estratégias de polidez é o de face, que é compreendida por Goffman (1981) tanto como os valores sociais positivos atribuídos aos membros de uma situação social, quanto como o território do 'eu' e suas liberdades de ação individuais. A partir de trabalhos que tomaram como base a conceituação de face feita por Erving Goffman, como o desenvolvido por Brown e Levinson (1987 [1978]), introduziu-se os conceitos de face negativa e face positiva: aquela sendo entendida como a liberdade de comportamento e o "território" do indivíduo em interação; e esta como o conjunto de imagens valorizantes os interlocutores constroem de si (e, eventualmente, tentam impô-las na interação), também havendo a contribuição das imagens valorizantes pré-construídas pelos membros de uma determinada situação social.

Nos estudos atuais acerca do uso da linguagem, já é tácito que, ao nos colocarmos em interação, agimos sobre os nossos interlocutores e, da mesma forma, os nossos interlocutores agem sobre nós, modificando-nos e interferindo de diferentes maneiras nas situações sociais nas quais estamos inseridos; isto é, produzimos atos de fala (AUSTIN, 1990 [1962] / SEARLE, 1995 [1979]). Tendo isso em vista, é possível afirmar que, na interação, "os interlocutores são levados a realizar um certo número de atos verbais e não verbais" (KERBRAT-ORECCHIONI, 2006, p.

\footnotetext{
2 Conceito de Goffman (2002[1975]) que está relacionado à situação imediata de uso da língua, sendo compreendido como o evento social em que estão inseridos os membros de determinada interação, no qual há a propensão e a disponibilidade dos indivíduos em interação para ocorrerem trocas comunicativas.
} 
78). É através das noções de face positiva e face negativa que se faz possível compreendermos que uma grande parte desses atos se apresenta enquanto uma ameaça para alguma das faces, tanto as do falante quanto as do(s) ouvinte(s). Percebendo esse fato, Brown e Levinson (1987 [1978]) propõem a noção de Face Threatening Acts (FTAs), os "atos ameaçadores à face".

De modo sucinto, podemos destacar: (i) os atos que ameaçam a face negativa do emissor, que podem ser percebidos num convite, numa oferta ou numa promessa, contextos em que o falante se compromete a lesar seu próprio território; (ii) atos que que ameaçam a face positiva do emissor, como numa autocrítica, em que o falante exerce um comportamento possivelmente autodegradante; (iii) atos que ameacam a face negativa do receptor, que podem ser observadas numa ordem ou numa proibição, em que o receptor tem sua liberdade de comportamento ameaçada, tendo assim o seu território violado; (iv) e os atos que ameaşam a face positiva do receptor, vistos numa refutação ou numa crítica, nas quais os imagens valorizantes do receptor são postas em risco.

Esse modelo de compreensão dos atos direcionados às faces dos interlocutores foi criticado por alguns teóricos por se mostrar extremamente pessimista, considerando as faces dos membros de uma situação social de modo sob constante ameaça. Sendo crítica em relação a isso, Kerbrat-Orecchioni (2006, p. 82) reafirma a relevância de se entender que "alguns atos de fala também podem ser valorizantes para essas mesmas faces, como o elogio, o agradecimento ou os votos". Desse modo, a autora, bebendo das teorias de Brown e Levinson (1987), reforça o que seria o lado oposto dos FTAs, os Face Flattering Acts (FFAs), sendo compreendidos exatamente como os efeitos positivos e valorizantes à face produzidos por um ato de fala.

\subsection{A polidez negativa e a polidez positiva}

Por meio do entendimento dos FTAs e dos FFAs, podemos finalmente chegar a uma compreensão mais bem-acabada da polidez - para tanto, iremos nos basear novamente em Kerbrat-Orecchioni (2006) -, sendo esta constituída por dois tipos de estratégias: a polidez negativa, que opera no sentido da mitigação das ameaças às faces e da preservação da harmonia, atenuando os possíveis efeitos de um FTA (como ao mitigar os efeitos de uma ordem, quando se direciona à face negativa, ou como quando é feita uma crítica, quando se refere à face positiva); e a polidez positiva, que opera no sentido da valorização das faces e da maximização da harmonia na interação, trabalhando com a apreciação de possíveis FFAs (por exemplo, efetuando alguma concessão, quando está se referindo à face negativa, ou um elogio, quando direcionada à face positiva).

De modo geral, a polidez negativa possui uma natureza mitigadora, evitando conflitos; já a polidez positiva é de natureza produtiva, buscando um envolvimento entre os participantes. A seguir, buscaremos expor alguns procedimentos de polidez negativa e positiva que possuímos, neste momento da pesquisa, como os mais imediatamente relevantes de serem estudados.

Iniciando pela polidez negativa, devemos destacar dois procedimentos gerais: os substitutivos e os acompanhantes. Do primeiro tipo de procedimento, podemos destacar como relevantes para o que foi identificado na pesquisa os seguintes fenômenos: (i) formulação indireta de um ato de fala, em que, por exemplo, em vez de ser feita uma ordem de forma direta como em "Feche a porta!", é feita uma pergunta como "Você poderia fechar a porta?"; (ii) desatualizadores modais, temporais ou pessoais, em que (continuando com o exemplo de uma "ordem", para dar um exemplo de desatualizador temporal) pode-se utilizar o passado de polidez para fazer a asserção "Eu queria que você fechasse a porta"; (iii) substituição de pronomes pessoais, como a já tácita troca do pronome "tu" por "você" ou, em casos mais acentuados de polidez, por "o(a) senhor(a)"; (iv) além dos usos de eufemismo, como no exemplo de enunciado "Não é muito inteligente tomar essa atitude", no lugar de simplesmente ser dito "É tolice fazer isso".

Já o segundo tipo de procedimento é produzido ao serem suavizados os efeitos de um FTA, utilizando-se de uma fórmula especializada para acompanhá-lo, as quais podemos destacar: (i) 
enunciado preliminar, que consiste em produzir um enunciado que preceda o FTA em si (sendo este, em geral, acompanhado ou substituído por mais um procedimento), como no enunciado "Você tem um momento?"; (ii) minimizadores, que se dá, em geral, pelo uso de advérbios que possuam, no enunciado em uso, uma função de minimização ou pela formação de diminutivos, como em "Eu só queria te pedir..." / "Você poderia fazer uma favorzinho?"; (iii) modalizadores, que consistem no uso de expressões (geralmente verbos e advérbios) que produzam efeitos de sentido reflexivos ou autorreflexivos, simulando uma distância entre o enunciador e o conteúdo do enunciado, o que pode ser percebido em construções como "Ele compreende que..." / "Entende-se que..." / "Eu penso que" / "Ela provavelmente dirá que..."; (iv) desarmadores, que consistem em antecipar e tentar neutralizar uma possível reação negativa do interlocutor, como em "Não quero ser arrogante, mas..."; (v) moderadores, que são mais comuns de serem vistos em enunciados construídos com vocativos mais afetuosos ou com algum adjunto adverbial que produza efeitos de gentileza, como em "Vamos à luta, companheiro!" / "Por favor, me dê seu documento".

Passando para a polidez positiva, devemos, antes de tudo, lembrar que esta estratégia é de natureza produtiva. Isto é, em vez de tentar evitar e/ou tentar atenuar um ato de fala, este tipo de polidez busca efetuar e/ou reforçar os efeitos de um possível FFA, para que haja a valorização da face dos interlocutores e a manutenção da harmonia da interação (KERBRAT-ORECCHIONI, 2006). Além de se apresentar enquanto uma estratégia interacional - que pode ser comumente percebida pelo uso de advérbios de intensidade com valores positivos e pela formação de aumentativos, como em "Isso está extremamente delicioso!" ou "Muitíssimo obrigado!" -, a polidez positiva é também um princípio da interação verbal, pois há diversas provas de que existe "um princípio de vontade que, de modo geral, conduz os falantes a suavizar a formulação dos atos ameaçadores e a reforçar a dos atos valorizantes" (KERBRAT-ORECCHIONI, 2006, p. 91-92).

É importante destacar ainda que, na análise feita neste trabalho, consideramos enquanto polidez não apenas a atenuação das ameaças às faces e a valorização das faces, mas também consideramos como polidez as estratégias de manutenção e/ou maximização do envolvimento e da harmonia da interação - este entendimento é de suma relevância para analisarmos as estratégias empreendidas na relação interpessoal entre autor da resenha e leitores. Para analisarmos a polidez sob estes aspectos, usaremos as categorias de expectativa de comportamento e de partilhamento de conhecimento buscando interpretar as diferentes estratégias empreendidas nos textos.

\section{Procedimentos metodológicos}

No trabalhado aqui desenvolvido, buscamos, antes de tudo, encontrar algumas das estratégias mais recorrentes de polidez e interpretá-las tendo em vista os conceitos de expectativa de conhecimento e de partilhamento de conhecimento. Para tanto, coletamos cinco resenhas acadêmicas que foram publicadas em diferentes periódicos Qualis A nos últimos cinco anos. Buscamos também identificar possíveis correlações entre os pontos de ocorrência das estratégias de polidez, suas respectivas funções discursivas para os textos e os aspectos composicionais do gênero resenha acadêmica.

Com fins metodológicos, tomamos como padrão de estrutura composicional das resenhas acadêmicas $^{3}$ o modelo descrito por Mota-Roth e Hendges (2010), que compreendem a resenha acadêmica estruturada com as seções: Apresentação $>$ Descrição $>$ Avaliação $>$ Recomendação (ou não) do livro - havendo a possibilidade de a Descrição e a Avaliação serem desenvolvidas simultaneamente. Assumimos, contudo, a Avaliação não como uma seção que ocorre após ou concomitantemente à Descrição, mas enquanto um processo que perpassa toda a resenha. Para as

\footnotetext{
3 Apesar de, com fins metodológicos, tomarmos um modelo, compreendemos que os gêneros textuais assumem formas relativamente estáveis, sendo determinadas de forma mais precisa pelos seus propósitos sociocomunicativos e pelo seu contexto de produção, circulação e compreensão (MARCUSCHI, 2008).
} 
autoras: a "Apresentação" se destina a introduzir a obra resenhada e seu autor, o tradutor (quando a obra resenhada é uma tradução), a perspectiva teórica desse autor e algumas outras que sejam complementares ou opostas; a "Descrição" se destina a detalhar as partes do livro, à medida que são feitos alguns comentários; e a "Recomendação (ou não) do livro" concerne à conclusão das análises feitas durante a resenha, recomendando (ou não) a obra, mesmo que de forma mais implícita - em todos textos analisados, as obras foram recomendadas, desse modo, chamaremos de "Recomendação".

Outro procedimento metodológico relevante que adotamos neste trabalho é a forma pela qual tratamos alguns dos participantes dessa interação escrita, para que não haja enganos na leitura deste trabalho: chamaremos o autor do texto doravante autor da resenha, ou autor apenas; o autor da obra resenhada doravante autor resenhado; quando a obra for estrangeira e possuir um tradutor, este será chamado doravante tradutor resenhado; os leitores especializados na área ou em área relacionadas serão chamados doravante especialistas; e o leitor usual da resenha será doravante chamado leitor comum, ou apenas leitor. Esta categorização se baseia no recente estudo de Santana e Barros (2017) acerca dos aspectos constitutivos da relação interpessoal no gênero resenha acadêmica, junto ao Nelfe/UFPE.

As resenhas selecionadas foram": (i) "Da África para o atlântico", de Mikael Parkvall, livro resenhado por Lilian do Rocio Borba (PUCCAMP) e Renato Miguel Basso (UFSCAR), resenha publicada na Revista da ABRALIN; (ii) "Morte e vitalidade das línguas indígenas e as pressões sobre seus falantes", de Terborg e García Landa, livro resenhado por Dorotea Frank Kersch (UNISINOS), resenha publicada na Alfa; (iii) "Humanização. Gênero. Poder. Contribuições dos estudos da fala-em-interação para atenção à saúde", de Osterman e Meneghel, livro resenhado por Alexandre José Cadilhe (UERJ), resenha publicada na Revista da ANPOLL; (iv) "História sociopolítica da língua portuguesa", de Carlos Alberto Faraco, livro resenhado por Marcos Bagno (UnB), resenha publicada no Caderno de Estudos Linguísticos; (v) "O português no século XXI: cenário geopolítico e sociolinguístico", de Moita Lopes, livro resenhado por Daniel do Nascimento e Silva (UNICAMP), resenha publicada na D.E.L.T.A.

\section{Resultados e discussão}

Através do que foi estudado até então, pudemos perceber a recorrência de algumas mesmas estratégias específicas de polidez negativa e polidez positiva em cada uma das resenhas do nosso corpus. Começaremos, no primeiro subtópico, discutindo a constante presença da polidez positiva nos primeiros e nos últimos parágrafos de cada resenha, relacionando essa presença recorrente à sua provável função para o gênero e para os textos em questão. Em seguida, buscaremos detalhar a relevância dos procedimentos substitutivos e acompanhantes de polidez negativa para entendermos as expectativas de comportamento e os partilhamentos de comportamento que estão em jogo nessas interações entre autor da resenha, autor resenhado, tradutor resenhado (quando houver) e leitor comum. Ao final, ainda traremos algumas quantificações de algumas generalizações que estão sendo trazidas nesta discussão de resultados e faremos breves considerações sobre tais números.

\subsection{A polidez positiva, a apresentação e a (não) recomendação}

Algo que pudemos perceber, logo inicialmente, é a presença recorrente de FFAs, direcionados ao autor resenhado e sua obra: (i) nos parágrafos iniciais das resenhas aqui trabalhadas, na seção que seria a de "Apresentação" dessas resenhas; (ii) e nos parágrafos finais, que fariam parte da "Recomendação (ou não) do livro". Quanto aos parágrafos iniciais, este fato

\footnotetext{
${ }^{4}$ Para maiores informações sobre esses textos, consultar as referências.
} 
se deu em quatro de cinco das resenhas estudadas, sendo a resenha (iv) a única a não apresentar tal característica, pois o autor constrói a Apresentação de sua resenha de modo peculiar, fazendo um apanhado histórico dos estudos sobre a história da língua portuguesa, até chegar na obra em questão e, de forma objetiva, apresentar o autor resenhado e seu livro - cedendo, contudo, à utilização dos FFAs na Recomendação do livro, nos parágrafos finais.

Vejamos a seguir o Exemplo 1, trecho do segundo parágrafo (seção de Apresentação) da resenha (v): "Se o que precisamos para nossa imaginação sobre línguas são novas metáforas, a obra cuidadosa e criticamente organizada por Luiz Paulo da Moita Lopes sobre o que se chama de português é abundante delas" (p. 426, grifos nossos). Neste trecho, é possível encontramos algumas adjetivações com efeitos valorizantes, como as expressões destacadas "cuidadosa" e "abundante", além do advérbio de modo "criticamente", que constituem formas de caracterização positiva da obra - direcionando-se não apenas à obra, mas, especialmente, à face positiva do autor resenhado.

As produções desses FFAs não se dão por acaso, de forma ingênua; pelo contrário, esses FFAs são: (i) por um lado, estratégias de legitimação dos discursos que estão por vir, pois, havendo críticas positivas, os elogios ao autor resenhado e à sua obra dariam uma "base lógica" para tais críticas; (ii) e, por outro lado, funcionariam como formas de atenuar já de forma prévia possíveis ameaças à face positiva do autor resenhado, caso haja críticas negativas no decorrer do texto.

Há ainda um caso mais complexo de polidez positiva, no que se refere às diferentes expectativas de comportamento do autor da resenha. Observemos o Exemplo 2, retirado do primeiro parágrafo da resenha (i): "Trata-se de uma primorosa tradução feita por Rodolfo Ilari da obra 'Out of Africa: African influences in Atlantic Creoles', escrita pelo renomado linguista sueco Mikael Parkvall, e publicada originalmente em 2000” (p. 339, grifos nossos). Neste caso, há não apenas um FFA direcionado à face positiva do autor resenhado, mas também à do tradutor resenhado. Apesar de essa ser a única resenha de obra traduzida dentro do nosso corpus, este "duplo FFA" nos leva à compreensão de que seria interpretado como impolido o tratamento elogioso apenas ao autor resenhado, ou apenas ao tradutor - no que diz respeito às expectativas de comportamento do próprio autor da resenha.

\subsection{Os procedimentos substitutivos de polidez negativa}

Um procedimento de polidez negativa que pudemos notar com maior frequência nas resenhas desta pesquisa foi o procedimento substitutivo de eufemismo. Leiamos a seguir o Exemplo 3 , retirado da resenha $(\mathrm{v})$ :

\footnotetext{
"Se o estado atual dos fluxos de capital simbólico e financeiro é diverso daquele vivenciado por Saussure, então a sociolinguística de O português no século XXI entendida, assim como a linguística aplicada e a pragmática, não como disciplina(s), mas como perspectiva(s) - demonstra serem necessárias outras ferramentas para entender as línguas e seus falantes" (p. 426, grifo nosso).
}

Podemos interpretar que, neste trecho, empreende-se um eufemismo enquanto estratégia de atenuação de uma possível ameaça à face positiva de possíveis leitores especialistas que que possam trabalhar com os pressupostos estruturalistas saussurianos, preservando assim uma possível harmonia na interação desses leitores com o texto; pois, em vez de afirmar de forma direta algo como "demonstra que já não mais cabe as ferramentas de estudo linguístico estruturalista", o autor busca minimizar os impactos do enunciado reformulando-o para "demonstra serem necessárias outras ferramentas".

Outra estratégia de polidez negativa comumente encontrada em nossa pesquisa é o procedimento substitutivo desatualizador temporal. Observemos um trecho (Exemplo 4) da resenha (ii):

"Velázquez acredita que, se forem estabelecidas pressões a favor do matlazinca por meio da implementação de estratégias vinculadas a essas pressões, será possível deter a 
mudança. Essas estratégias incluiriam, por exemplo, promoção de um maior uso e transmissão da língua e inclusão de benefícios tangíveis para os membros da comunidade" (p. 704, grifo nosso).

Neste excerto, encontramos, através da palavra "incluiriam", a presença do que seria um "futuro de polidež" enquanto desatualizador temporal, que se constitui pela seleção de determinado tempo verbal (o futuro do pretérito, em vez do presente) que possibilita um certo distanciamento em relação que está sendo dito, protegendo a sua face positiva de possiveis julgamentos feitos pelo leitor acerca de sua expertise sobre o que está sendo dito - funcionando, assim, de modo semelhante à categoria de "passado de polidez".

Também reincidente foi o procedimento de formulação indireta dos atos de fala, o qual podemos observar no Exemplo 5, retirado dos parágrafos finais (seção de Recomendação) da resenha (i):

"Não podemos deixar de dizer, novamente, que a obra de Parkvall nos faz pensar muito sobre a formação do PBV e os paralelos possíveis a serem traçados. Não seria incorreto dizer que hoje, apesar de visíveis e importantíssimos progressos, ainda não temos uma análise tão profunda e ampla com relação à história e formação do PBV quanto aquela desenvolvida por Parkvall para os crioulos atlânticos” (p. 349, grifo nosso).

No trecho em destaque, além de mais um exemplo de uso do "futuro de polidez" (com a conjugação do verbo na forma "seria", em vez da forma no presente "é"), encontramos uma formulação indireta de um ato de fala, pois elogiar excessivamente algo que já possui sua autoridade teórica questionada - mesmo que por teorias sem "uma análise profunda e ampla" -, que já é alguma medida "datado", seria pôr em xeque a própria face positiva. Isto é, há uma atenuação de um ato direcionado à face positiva do autor resenhado, que, por sua vez, acaba por minimizar uma ameaça à própria face do autor da resenha para que não haja uma ameaça à face positiva do próprio autor. Um fato intrigante é que isso ocorre exatamente na Recomendação, onde seria, como já vimos, o espaço mais propício para a produção de FFAs; estas passam, desse modo, a ser atenuadas, pois aceitar por completo as proposições teóricas de um autor é um risco na interação acadêmico-científica, é em certa medida negar as proposições de outros autores.

Para explicar essa espécie de "contradição interacional", poderíamos pensar na noção de duplo vínculo (BATESON, 1972), que consiste fundamentalmente em situações em que o participante é orientado a respeitar, ao mesmo tempo, dois princípios interacionais - no caso do fenômeno em análise no Exemplo 5, o princípio de ser minimamente elogioso quando se produz uma crítica ao trabalho do outro e o princípio de não valorizar demais uma posição (não ser excessivamente parcial).

\subsection{Os procedimentos acompanhantes de polidez negativa}

Quanto a este tipo de procedimento de polidez negativa, pudemos notar a utilização muito frequente de procedimentos acompanhantes desarmadores, nos quais o autor percebe que determinado conhecimento acerca do conteúdo do livro pode não ser partilhado pelo seu leitor e, desarmando uma possível reação de estranhamento ao que está sendo dito - o que prejudicaria o envolvimento entre o leitor e o texto -, adianta-se a explicar melhor o que já foi informado. $\mathrm{O}$ Exemplo 6, retirado da Descrição da resenha (iii), demonstra uma realização desse procedimento: "Nesse capítulo, as autoras investigam interações onde são emergentes situações compreendidas como delicadas, ou seja, quando ocorre uma mudança na orientação interacional dos participantes, resultada de perturbações" (p. 439, grifo nosso). Utiliza-se, nesse trecho, a expressão com valor conjuntivo "ou seja", que é fundamental para a conexão entre uma possível ameaça ao envolvimento da interação e o procedimento desarmador.

Outro exemplo de procedimento desarmador comumente utilizado nas resenhas analisadas (Exemplo 7) pode ser encontrado no seguinte trecho da resenha (iv): "[...] as diversas comunidades linguísticas, reservando um lugar secundário aos fenômenos de natureza 
propriamente linguística (fonéticos, morfossintáticos, lexicais etc.)" (p. 186, grifo nosso). Neste caso, contudo, a especificação do conhecimento que, para o autor, pode não ser partilhado pelo leitor comum vem detalhado entre parênteses.

Funcionando de modo muito semelhante a esse procedimento, temos também os enunciados preliminares. Observemos o Exemplo 8, localizado na seção de Recomendação da resenha (ii):

"Retomando a paráfrase da epígrafe, não custa lembrar que a sobrevivência das línguas está ligada à sobrevivência dos seus falantes, que precisam de identidades fortes e atitudes positivas em relação a si e à língua que falam, para que se interessem em transmiti-la às gerações seguintes, uma das condições para a vitalidade de uma língua" (p. 705, grifo nosso).

No caso desse procedimento, podemos observar uma forma de marcar (ou rememorar) o discurso de um outro. Isso se dá aparentemente com o objetivo de reforçar a conclusão que está sendo feita acerca do trabalho resenhado - tendo em vista que esse é o trecho final do último parágrafo da resenha -; à medida que também se desenvolve uma estratégia de fortalecimento do envolvimento dos leitores para com o texto, ao resgatar o que foi dito/citado no início do texto, na abertura da resenha.

Também foi comum encontrarmos a utilização de procedimentos acompanhantes modalizadores, em que o autor reflete sobre o que está sendo dito e se distancia. Tomemos como objeto de análise o Exemplo 9, advindo da resenha (i): "A questão de fundo nos estudos dos pidgins e crioulos, segundo o autor, é entender como funcionam o contato linguístico e a reestruturação das funções de cada língua" (p. 340, grifo nosso). Percebe-se uma função de distanciamento do dito mais uma vez a delimitação do discurso do outro - e, através dessa delimitação, uma função de responsabilização do autor resenhado nessa estratégia; pois, ao fazer isto, o autor da resenha protege a sua face positiva de possíveis julgamentos feitos pelo leitor, novamente, acerca de sua expertise no assunto em questão.

Mesmo que em menor número, uma outra estratégia repetidamente utilizada foi o procedimento acompanhante minimizador, no qual o autor buscava diminuir o impacto do que estava sendo dito geralmente por meio de alguma partícula adverbial. Vejamos o Exemplo 10, retirado da seção de Apresentação da resenha (iv):

"Exemplo típico dessa abordagem é a conhecida História da língua portuguesa de Paul Tessier (publicada na França em 1980), em que os "fatos históricos ocupam, em cada capítulo, duas ou três páginas, contra uma descrição muito mais detalhada dos 'fatos linguísticos'. Essa preocupação quase exclusiva com “a língua em si” atinge seu ápice com os chamados neogramáticos [...]” (p. 185, segundo grifo nosso).

Atentemos para o segundo grifo, que é de fato nosso. Nota-se nesse trecho que, à medida que se alinha à perspectiva teórica do autor resenhado, o autor da resenha constrói uma crítica negativa às perspectivas "mais tradicionais" e, consequentemente, aos seus adeptos, ameaçando a face positiva desses interlocutores; servindo então o advérbio "quase" como uma forma minimizadora, sendo essa um exemplo bastante prototípico de mitigação de ameaças às faces. Ao mesmo tempo, esse advérbio aparenta também possuir a função de não se criar generalizações imprecisas, algo bastante evitado no domínio discursivo acadêmico-científico, sendo o autor que as faz mal visto - assegurando ao autor da resenha, também dessa forma, a sua expertise no tema da obra, protegendo a sua própria face positiva.

\subsection{Quantificação de alguns dados analisados}

Através dos resultados apontados neste trabalho, podemos destacar alguns números mais relevantes para que possamos embasar as análises aqui empreendidas e para que produzamos 
algumas generalizações. Observemos, para tanto, o quadro ${ }^{5}$ a seguir com algumas estratégias de polidez percebidas nos pontos de ocorrência que dividimos em seções de "Apresentação", "Descrição" e "Recomendação". É importante destacar, antes de tudo: tanto que tal quantificação está sempre passível a recontagem, a depender do olhar interpretativo do pesquisador; quanto que os fenômenos destacados a seguir são um recorte de toda a análise, estando presentes as ocorrências observadas de forma mais recorrente.

\begin{tabular}{|c|c|c|c|c|c|c|c|c|c|c|c|c|c|}
\hline & \multicolumn{3}{|c|}{ Apresentação } & \multicolumn{3}{|c|}{ Descrição } & \multicolumn{3}{|c|}{ Recomendação } & \multirow{2}{*}{\multicolumn{2}{|c|}{ TOTAL }} \\
\hline & & & $\mathrm{PF}$ & ATE & LC & PF & ATE & LC & PF & ATE & LC & & \\
\hline \multicolumn{3}{|c|}{$\begin{array}{c}\text { Estratégias de Polidezpositiva } \\
\text { mais explicitas }\end{array}$} & 0 & 7 & 0 & 0 & 4 & 0 & 0 & 9 & 0 & \multicolumn{2}{|c|}{20} \\
\hline \multirow{7}{*}{$\begin{array}{c}\text { Estratégias } \\
\text { de Polidez. } \\
\text { negativa }\end{array}$} & \multirow{3}{*}{$\begin{array}{l}\text { Procedim. } \\
\text { Substit. }\end{array}$} & Form. & 1 & 3 & 0 & 1 & 2 & 0 & 2 & 4 & 0 & 13 & \multirow{3}{*}{34} \\
\hline & & Desat. & 2 & 1 & 0 & 6 & 1 & 0 & 1 & 0 & 0 & 11 & \\
\hline & & Euf. & 1 & 6 & 0 & 0 & 1 & 0 & 0 & 2 & 0 & 10 & \\
\hline & \multirow{4}{*}{$\begin{array}{l}\text { Procedim. } \\
\text { Acomp. }\end{array}$} & E. P. & 2 & 4 & 5 & $\overline{0}$ & 1 & 1 & 2 & $\overline{1}$ & 3 & 19 & \multirow{4}{*}{72} \\
\hline & & Min. & 1 & 4 & 0 & 2 & 3 & 0 & 2 & 5 & 0 & 17 & \\
\hline & & Mod. & 5 & 3 & 0 & 3 & 1 & 0 & 4 & 2 & 0 & 18 & \\
\hline & & Des. & 0 & 1 & 6 & 0 & 3 & 2 & 0 & 2 & 4 & 18 & \\
\hline \multirow{2}{*}{\multicolumn{3}{|c|}{ TOTAL }} & 13 & 29 & 11 & 12 & 16 & 3 & 11 & 22 & 7 & & \\
\hline & & & \multicolumn{3}{|c|}{53} & \multicolumn{3}{|c|}{31} & \multicolumn{3}{|c|}{42} & & \\
\hline
\end{tabular}

As totalizações dessa quantificação das ocorrências estudadas nos leva a perceber alguns dados mais proeminentes, tais como: a) o número de vezes em que percebemos a utilização de estratégias de polidez negativa foi mais de cinco vezes maior que as utilizações de estratégias de polidez positiva; b) quanto às ocorrências de polidez negativa, a quantidade de procedimentos acompanhantes foi mais de duas vezes maior que a de procedimentos substitutivos; c) as estratégias de polidez foram mais recorrentes nas seções de Recomendação e Apresentação (especialmente esta) que na Descrição; d) nos somatórios de ocorrências em cada uma das três seções adotadas metodologicamente, a proteção à face do autor resenhado, tradutor resenhado, ou ainda de especialistas era a mais recorrente; e) nos somatórios de cada uma das seções, a proteção à própria face do autor da resenha foi a segunda mais observada; f) nas somas das ocorrências em cada uma das seções, a proteção à face do leitor comum foi a menos empreendida.

\section{CONSIDERAÇÕES FINAIS}

Assim como sugerido na hipótese inicial, os resultados indicam que há, de fato, correlações entre os aspectos composicionais do gênero resenha acadêmica e os pontos de ocorrência das estratégias de polidez positiva e polidez negativa. Em geral, pudemos perceber a presença de diferentes funções das estratégias percebidas e analisadas para o propósito comunicativo e sociodiscursivo da seção do texto na qual elas se apresentavam. Isto é, interpretamos que existe uma relação de interdependência entre as funções sociointeracionais/interpessoais das estratégias de polidez e a estrutura composicional do gênero resenha acadêmica.

\footnotetext{
${ }^{5}$ As abreviaturas e siglas significam: Form. = Formulação indireta dos atos de fala; Desat. = Desatualizadores; Euf. $=$ Eufemismo; E. $P .=$ Enunciado preliminar; Min. $=$ Minimizadores; Mod. $=$ Modalizadores; Des. $=$ Desarmadores; $P F$ $=$ Protegendo a própria face do autor da resenha; ATE = Protegendo a face do autor resenhado, do tradutor resenhado, ou de especialistas; $L C=$ Protegendo a face do leitor comum.
} 
Partindo disso, podem ser feitas quatro maiores generalizações:

a) Há uma predominância de estratégias mais explícitas de polidez nas seções de Apresentação e Recomendação. Acreditamos que isso se dá por haver uma maior presença de propósitos interacionais que privilegiam a materialização linguistico-textual das relações interpessoais em jogo nesse tipo de interação escrita.

b) Há a ocorrência da maior parte das estratégias mais explícitas de polidez positiva na Apresentação e na Recomendação; exatamente, como já afirmamos, por essas seções se apresentarem como "lugares" mais viáveis para a materialização de estratégias de envolvimento mais objetivas, chegando até a serem diretamente elogiosas. O que não significa que esse é um território exclusivo da polidez positiva, como vimos em alguns trechos trazidos aqui (Exemplos 5 , 8 e 10).

c) Nos parágrafos destinados à Descrição, encontramos um "lugar" em que é mais recorrente o uso de estratégias mais sutis, sendo mais comum a mitigação de possíveis ameaças (críticas negativas mais acentuadas) do que a busca por uma valorização às faces. Ou seja, essas seções são um território praticamente exclusivo da polidez negativa, que pode se materializar, a depender da situação, em procedimentos diversos - apesar de termos mapeado alguns que são mais recorrentes, as escolhas que os autores fazem por cada procedimento devem ser estudadas de modo situado em cada contexto interativo, analisando cada texto de forma distinta.

d) $\mathrm{Na}$ observação das ocorrências de polidez negativa, é muito mais comum encontrarmos: primeiramente, uma busca do autor da resenha por mitigar possíveis ameaças à própria face positiva, assegurando a sua expertise no assunto em questão; e também mais procedimentos acompanhantes que substitutivos, o que acreditamos estar relacionado ao próprio processo de escrita acadêmica da área que coletamos as resenhas (Letras/Linguística) - talvez, se coletássemos resenhas de outras áreas, a busca por uma objetividade científica e "exata" não permitisse essa maior recorrência de procedimentos textuais que "meramente" acompanham, ornam o que se quer dizer.

\section{REFERÊNCIAS}

AUSTIN, John. Quando dizer é fazer. Porto Alegre: Artes Médicas, 1990 [1962].

BARROS, Kazue S. M. de. Polidez em textos acadêmicos escritos. Congreso Latinoamericano de Estudios del Discurso, 8, 2009. Monterrey. Trabalho apresentando... s.p.

BATESON, Gregory. A theory of play and fantasy. In.: Steps to an ecology of mind. New York: Ballantine, 1972. p. 177-193.

BROWN, Penelope; LEVINSON, Stephen. Politeness: some universals in language usage. Cambridge: Cambridge University, 1987 [1978].

FARACO, Carlos Alberto. História sociopolítica da língua portuguesa. São Paulo: Parábola, 2016. Resenha de: BAGNO, Marcos. História sociopolítica da língua portuguesa, de Carlos Alberto Faraco (São Paulo, Parábola Editorial, 2016, 400 pp.). Caderno de Estudos Linguísticos, v. 58, n. 1, p. 185-192, abr. 2016.

GOFFMAN, Erving. A representação do eu na vida cotidiana. 20. ed. Petrópolis: Vozes, 2002 [1975].

\footnotetext{
${ }^{6}$ Claro que compreendemos que o "como se diz" é, em questão de língua enquanto interação social, tão importante quando "o que se diz", ou "o que se quer dizer".
} 
Forms of talk. Philadelphia: University of Pennsylvania, 1981.

KERBRAT-ORECCHIONI, Catherine. Análise da conversação: princípios e métodos. São Paulo: Parábola, 2006.

MARCUSCHI, Luiz Antônio. Análise da Conversação. 5. ed. São Paulo: Ática, 2003. 2008.

Produção textual, análise de gêneros e compreensão. São Paulo: Parábola Editorial,

MOITA LOPES, Luiz Paulo [org.]. O português no século XXI: cenário geopolítico e sociolinguístico. São Paulo: Parábola, 2013. Resenha de: SILVA, Daniel do Nascimento. Moita Lopes, L.P. (Org.). 2013. O português no século XXI: Cenário geopolítico e sociolinguístico. São Paulo: Parábola. D.E.L.T.A., v. 30, n. 2, p. 425-437, 2014.

MOTA-ROTH, Désirée; HENDGES, Graciela Rabuske. Produção textual na universidade. São Paulo: Parábola, 2010.

OSTERMAN, Ana Cristina; MENEGHEL, Stela Nazareth. Humanização. Gênero. Poder. Contribuições dos estudos da fala-em-interação para atenção à saúde. Campinas: Mercado das Letras \& Fiocruz, 2012. Resenha de: CADILHE, Alexandre José. Linguagem \& práticas de saúde: por uma interação entre campos. Revista da ANPOLL, v.1, n. 34, p. 437-444, jun. 2013.

PARKVALL, Mikael. Da África para o Atlântico. Campinas: Unicamp, 2012. Resenha de: BORBA, Lilian do Rocio; BASSO, Renato Miguel. Mikael Parkvall, Da África para o Atlântico: Campinas, Editora da Universidade Estadual de Campinas, 2012. Revista da ABRALIN, v. 11, n. 2, p. 339-351, dez. 2012.

SANTANA, Gabriel; BARROS, Kazue S. M. de. Aspectos constitutivos da relação interpessoal no gênero resenha acadêmica. Congresso Internacional da Abralin, 10, 2017. Niterói. Anais... s.p.

SEARLE, John. Expressão e significado. São Paulo: Martins Fontes, 1995 [1979].

SPENCER-OATEY, Helen. (Im)Politeness, Face and Perceptions of Rapport: Unpackaging their Bases and Interrelationships. Journal of Politeness Research, v. 1, n. 1, p. 95-119, jul. 2005.

TANNEN, Deborah. Conversational style: analyzing talk among friends. New York: Ablex Publishing. 1984.

TERBORG, R.; GARCÍA LANDA, L. Muerte y vitalidad de las lenguas indígenas y las presiones sobre sus hablantes. México: UNAM: CELE, 2011. Resenha de: KERSCH, Dorotea Frank. Morte e vitalidade das línguas indígenas e as pressões sobre seus falantes. Alfa, v. 59, n. 2, p. 697 705, 2013.

Recebido em 31/05/2017

Aceito em 14/08/2017

Publicado em 15/08/2017 